\title{
EFFICACY OF ONDANSETRON CONTINUOUS INFUSION AND BOLUS INTRAVENOUS FOR POSTOPERATIVE NAUSEA AND VOMITING
}

Rina Saputri ${ }^{1 * \dagger}$

${ }^{1}$ Faculty of Pharmacy, Surabaya University Indonesia

*rinasaputri@stikessarimulia.ac.id

\author{
Abdul Rahem² \\ ${ }^{2}$ Faculty of Pharmacy, Airlangga University Indonesia \\ rahem_yakersuda@yahoo.com \\ Anita Purnamayanti ${ }^{1}$ \\ ${ }^{1}$ Faculty of Pharmacy, Surabaya University Indonesia \\ anita_p_rahman@yahoo.com
}

\begin{abstract}
Objective: This study was conducted to compare the efficacy and side effects of Ondansetron continuous infusion compared with ondansetron bolus intravenous in the postoperative patient.

Methods: The research method used was case control. Data were analyzed using Mann Whitney test and analytic assessment using evidence-based medicine principals. The test group receiving Ondansetron continuous infusion consisted of 11 patients and the controlled group with Ondansetron bolus intravenous consisted of 6 samples.

Results: The results show the efficacy of Ondansetron continuous infusion on the first day was better, but on the second and third days there was no difference in efficacy. Side effects of dizziness on the first day was lower in the test group Ondansetron continuous infusion, but on the second and third days, there was no difference. There were no differences on the side effect of constipation between the groups. The results of Ratio Risk showed that risk of nausea-vomiting and dizziness of Ondansetron continuous infusion were lower, but the risk of constipation was higher.

Conclusion: Efficacy of Ondansetron continuous infusion was better. The side effects of dizziness in the continuous infusion group were fewer, but the side effect of constipation was higher.
\end{abstract}

Keyword: Bolus Intravenous, Continuous infusion, Ondansetron, PONV

\section{INTRODUCTION}

One of the problems that often occur postoperatively is nausea and vomiting. The incidence of postoperative vomiting reached $30 \%$, and the incidence of nausea reached $50 \%$. In patients at high risk of nausea and vomiting incidence reached $80 \%$. One of the most recommended drugs to overcome nausea and vomiting is the 5-HT3 receptor antagonist group Ondansetron, the only widely studied antiemetic group, especially for postoperative nausea and vomiting. Ondansetron is the most commonly used drugs as an antiemetic compared to others because of its efficacy and safety [1]. 
The results of Song et al (2008) showed that the use of ondansetron can be given by two techniques of continuous infusion and intravenous bolus [2]. In Sari Mulia Hospital Banjarmasin, there are differences in postoperative ondansetron administration technique given by continuous infusion, drip for $2 \times 24$ hours with $3 \times 8 \mathrm{mg}$ dose, or given by intravenous bolus at $3 \times 8 \mathrm{mg}$ daily for 2 days. The efficacy and side effects of these two different administration techniques are not known which one is better.

This study was conducted to compare the efficacy and side effects of Ondansetron continuous infusion compared with Ondansetron bolus intravenous in the postcesarean section or laparotomy sample at Sari Mulia Hospital Banjarmasin. It is expected that this research can provide information to the hospital so that the quality of health services can be improved.

\section{METHODS}

The research design used was case control. The affordable population in this study was all cesarean or laparotomy patients treated in November 2015 - January 2016 at Sari Mulia Banjarmasin Hospital receiving treatment Ondansetron continuous infusion or Ondansetron intravenous bolus according to the study criteria.

The sample in this study will be divided into 2 groups: a group of cesarean section patients receiving continuous infusion therapy Ondansetron $8 \mathrm{mg} 3$ ampoule for 2 days (24 mg) and group of caesarean section patients receiving intravenous bolus therapy Ondansetron $8 \mathrm{mg} 3$ ampoule per day with administration for 2 days $(48 \mathrm{mg})$. Provision of Ondansetron antiemetic type based on therapy given by the doctor. The description of the time of Ondansetron and Morphine administration in this study can be seen in Figure 1.

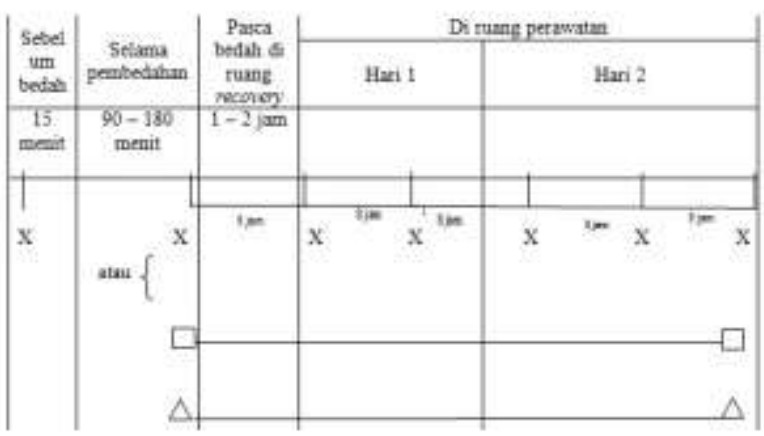

Notes :

$\mathrm{X}=$ Ondansetron intravenous bolus

$\square=$ Ondansetron continuous infusion

$\triangle=$ Epidural continuous infusion Morphine

Figure 1. Timing of Ondansetron and Morphine

Measurement of the efficacy of Ondansetron administration in Overcoming Nausea Vomiting After Cesarean or Laparotomy using research instrument in the form of a numerical score for postoperative nausea and vomiting (PONV) at the time preoperative, postoperative in recovery room, the first day of the wards, second day, and the third day. Measurement of side effects Ondansetron administration by looking at the frequency of dizziness and constipation 
experienced by patients during the use of Ondansetron. Measurement of side effects of dizziness using numerical and verbal pain scale performed prior to operative to see if dizziness had occurred prior to Ondansetron administration, then measured on the first day of the wards, the second day, and the third day. Measurement of the side effects of constipation by looking at the frequency of chapter samples on the first day until the third day, measuring the constipation scoring system to see the history of the sample preoperative, to determine whether the sample had been constipated preoperative or constipation occurred postoperatively due to use of Ondansetron. Measurement of the side effects of constipation also by measuring the shape of feces by using the Bristol fecal scale. Assessment of drug side effects also uses the Naranjo scale, which aims to identify the side effects of drugs more quantitatively, so it can be known which drug has the potential to cause these side effects.

Data analysis was done by using computer analysis by using nonparametric analysis because of abnormal data distribution with Mann -Whitney method. In addition, the analysis conducted in this study also uses analytic analysis with the principle of evidencebased medicine (EBM).

\section{RESULTS}

The results of data collection during November 2015 to January 2016 were 38 samples who underwent cesarean section and laparotomy, but only 17 samples were included in inclusion criteria. 21 samples did not meet the inclusion criteria because the samples received postoperative opioid non morphine epidural. 17 samples included in inclusion criteria consisted of groups receiving Ondansetron continuous infusion treatment of 11 samples and Ondansetron intravenous bolus group of 6 samples. The data of characteristic of the research sample can be seen in table 1 . The type of anesthetic drug used in the research can be seen in table 2. Mann Whitney test results and analytic analysis with evidencebased medicine $(\mathrm{EBM})$ principle against the efficacy and side effects ondansetron continuous infusion group with bolus intravenous can be seen in table 3 .

Table 1. Data characteristics

\begin{tabular}{|c|c|c|c|c|}
\hline & \multicolumn{4}{|c|}{ Type operative } \\
\hline & \multicolumn{2}{|c|}{ Cesarean } & \multicolumn{2}{|c|}{ Laparotomy } \\
\hline & $\begin{array}{c}\text { Continuous } \\
\text { infusion }\end{array}$ & Bolus iv & $\begin{array}{c}\text { Continuous } \\
\text { infusion }\end{array}$ & Bolus iv \\
\hline Age & & & & \\
\hline $21-25$ & 1 & - & - & - \\
\hline $26-30$ & - & - & - & - \\
\hline $31-35$ & 1 & - & - & - \\
\hline $36-40$ & 2 & 1 & 3 & 1 \\
\hline $41-45$ & - & 1 & 1 & 2 \\
\hline $46-50$ & - & - & 3 & 1 \\
\hline \multicolumn{5}{|c|}{ Smoking status } \\
\hline Yes & - & - & - & - \\
\hline No & 4 & 2 & 7 & 4 \\
\hline \multicolumn{5}{|c|}{ Liver disorder status } \\
\hline Yes & - & - & - & - \\
\hline No & 4 & 2 & 7 & 4 \\
\hline
\end{tabular}




\begin{tabular}{lcccc}
\hline \multicolumn{2}{l}{ History of dyspepsia } & & & \\
\hline Yes & - & 1 & 2 & 1 \\
\hline No & 4 & 1 & 5 & 3
\end{tabular}

Table 2. Type of anesthetic drugs

\begin{tabular}{lccc}
\hline \multirow{2}{*}{$\begin{array}{r}\text { Route of } \\
\text { granting }\end{array}$} & \multicolumn{2}{c}{ Anaesthetic agent } & amount \\
\cline { 2 - 3 } & Ropivacaine & Bupivacaine & \\
\hline $\begin{array}{l}\text { Continuous } \\
\text { infusion }\end{array}$ & 7 & 4 & 11 \\
\hline Bolus iv & 2 & 4 & 6 \\
\hline
\end{tabular}

Table 3. Research result

\begin{tabular}{|c|c|c|c|c|}
\hline & $\begin{array}{l}\text { Asymp.Sign. } \\
\text { ( } 2 \text { tailed) }\end{array}$ & & $\mathrm{RR}$ & $\begin{array}{l}\text { NNT/ } \\
\text { NNH }\end{array}$ \\
\hline \multicolumn{5}{|l|}{ Efficacy } \\
\hline During operative & 0,176 & Mean & 0,45 & NNT \\
\hline $\begin{array}{l}\text { Postoperative in } \\
\text { the recovery }\end{array}$ & 0,176 & $\begin{array}{c}\text { Rank } \\
\quad:\end{array}$ & & $=2$ \\
\hline room & & 7,41 & & \\
\hline Day 1 & 0,039 & and & & \\
\hline Day 2 & 0,101 & 11,92 & & \\
\hline Day 3 & 0,416 & & & \\
\hline \multicolumn{5}{|l|}{ Side effect } \\
\hline Dizzy & & Mean & 0,8 & $\mathrm{NNH}$ \\
\hline Day 1 & 0,006 & Rank & & $=5$ \\
\hline Day 2 & 0,080 & $: 6,20$ & & \\
\hline Day 3 & 0,064 & $\begin{array}{l}\text { and } \\
12,33\end{array}$ & & \\
\hline \multicolumn{5}{|l|}{ Side effect } \\
\hline \multicolumn{5}{|l|}{ Constipation } \\
\hline Day 1 & 0,176 & & 1,1 & $\mathrm{NNH}$ \\
\hline Day 2 & 0,590 & & & $=13$ \\
\hline effect & & & & \\
\hline \multicolumn{5}{|l|}{ Morphine } \\
\hline \multicolumn{5}{|l|}{ Itchy } \\
\hline Day 1 & 0,939 & & 0,55 & $\mathrm{NNH}$ \\
\hline Day 2 & 0,495 & & & $=7$ \\
\hline
\end{tabular}

\section{DISCUSSION}

Limitations of this study include the small number of samples when tested for normality with the help of computer analysis following the distribution is not normal, so that the analytical aid used is a non-parametric method. Provision of epidural continuous infusion of Morphine and Ondansetron continuous infusion at the same time, simultaneously at the end of the surgery and remain given simultaneously for 2 days, making it difficult to distinguish drug side effects of dizziness and constipation.Adverse effects of dizziness and constipation cannot be observed during epidural Morphine at a temporary stop due to itching side effects. As a result, the Naranjo gauge can not be applied as a whole in determining the side effects of dizziness and constipation.

The majority of the most samples in this study were between the ages of 36-40 years. Pregnancy over age 35 is a high-risk pregnancy, for mothers and infants so that their attendance is more assisted by cesarean section, especially for mothers who have had a cesarean section in their previous labor [3]. The smoking status of all samples included in the study was $100 \%$ of the sample did not smoke. Patients with a history of never smoking had a higher risk of nausea and vomiting than patients who had smoked, so all of the samples in this study were at risk for postoperative nausea and vomiting. In this study, the status of hepatic impairment is not a nuisance variable because all samples do not have hepatic disorders. In this study, there were 4 samples with a history of dyspepsia. 
Patients with a history of dyspepsia are at high risk for postoperative nausea and vomiting [1,4$5]$.

Anesthetic agents used are Ropivacaine and Bupivacaine. The results of this study are descriptive and based on the Mann Whitney test showed no differences in side effects of nausea and vomiting between the two uses of the drug. This result is consistent with previous studies showing that the use of Ropivacaine and Bupivacaine is as effective in treating pain, and there is no significant difference between the two drugs in the side effects of nausea and vomiting [6]

Measurement of differences in the efficacy of therapy during operative and postoperative in the recovery room was descriptive in the pattern of all samples did not experience nausea and vomiting in the administration of Ondansetron infusion continuous, whereas in the Ondansetron bolus intravenous group there was 1 sample experiencing nausea, this is because the patient has a history of dyspepsia and patients experience anxiety because they have had a miscarriage 4 times, and labor is now the second birth and is the sixth pregnancy. This is consistent with the theory of the history of dyspepsia and anxiety is a risk factor for nausea and vomiting [1, 4]. Based on the measurement results with the help of computer analysis showed no difference between the two groups.
Measurement of differences in the efficacy of therapy on the first day descriptively there was a pattern of 1 person experiencing nausea and 1 person who experienced vomiting on the administration of Ondansetron infusion continuous, whereas in the bolus intravenous group almost all patients experienced nausea and vomiting. Based on the results of measurements with the help of computer analysis, it shows there is a difference between the two groups on the first postoperative day, where the continuous infusion is more effective. This result is consistent with one of the advantages of continuous infusion preparations that can keep the blood drug remained constant over a long period of time, preventing peak fluctuations (maximum) and trough (minimum) levels of the drug in the blood, thus providing better efficacy [7 - 8].

Measurement of efficacy differences in the second and third days descriptively there was a pattern in both groups, almost all patients experienced nausea and vomiting. In the Ondansetron continuous infusion group, there was an improvement in the incidence of nausea and vomiting from the second day of the third day. In the Ondansetron bolus intravenous group, the relative intensity of nausea and vomiting was comparable between patients who experienced improvement or remained nauseous and vomited on the third day. Based on the measurement results using computer analysis aid, there was no difference in the two 
groups. The greater incidence of nausea and vomiting on the second and third days, most likely caused by opioids (Morphine) is used. According to some literature, nausea, and vomiting caused by anesthesia medication occur after 0 - $24 \mathrm{~h}$ postoperative [9 - 10]. In this study used is epidural Morphine, where the risk of nausea and vomiting is greater, but the efficacy in overcoming pain is better [11 - 13]. Opioids (Morphine) can cause gastric emptying and trigger vomiting reflexes in the vestibule and in gastrointestinal receptors [14]. If calculated time to reach epidural Morphin steady level of 8 - 28 hours $(4-7 \times \mathrm{t}$ 1/2), meaning between 8 - 28 hours post Morphine in epidural continuous infusion, Morphine levels are constant at all times until the end of Morphine in the day second in the treatment room. This means that the risk of side effects of nausea and vomiting is higher on the second day. Morphine first achieves steady-state compared to continuous infusion of Ondansetron or intravenous bolus which takes 12 to 42 hours to achieve steady levels. If Ondansetron is given to combat intravenous bolus nausea and vomiting, Ondansetron is present in the blood at the highest levels, then decreases at any time until the next dose. If given by continuous infusion rate, the blood drug level is always constant after the steady level is reached after 12 - 42 hours. Based on these pharmacokinetic data, both ondansetron continuous infusion and Morphine continuous infusion epidural have both reached steady levels. If seen from the data, the continuous infusion should be able to overcome the side effects of nausea and vomiting caused by epidural Morphine, but the factors that cause increased incidence of adverse events on the second day not only caused by the use of Morphine, but also because patients have started to mobilize to learn to stand and walking, and also because the patient has started consuming food, so the risk of nausea and vomiting on the second and third day is greater than the first day $[1,5]$.

The results of the analytic analysis with EBM principles to determine the efficacy of therapy showed if the risk of nausea and vomiting on the continuous intravenous drip Ondansetron 54.6\% lower than the intravenous bolus Ondansetron. The results of the number need to treat (NNT) analysis indicate the need for continuous intravenous administration of Ondansetron to 2 samples to cause therapeutic efficacy. The NNT value close to 1 means the more effective, so NNT can be used as an efficacy parameter.

In this study also found drug side effects of the emergence of itching that starts from the nose and then to the head and up to the whole body. Measurement of side effects is itchy by looking at the frequency and intensity of the itch that appears postoperative on the first day until the third. 
Measurement of differences in side effects in the form of dizziness on the first day descriptively there is a pattern of 3 people who experience dizziness with mild to moderate pain scale in the continuous infusion group, whereas in the Ondansetron bolus intravenous group almost all patients experienced dizziness with a mild to very severe scale. The results of measurements using computer analysis aid show Ondansetron continuous infusion causing fewer side effects of dizziness. This is in accordance with the theory, where in the continuous infusion group there are no peak levels, so the side effects are relatively mild [78].

Measurements on the second and third days are descriptive there are patterns in both groups, almost all patients experience dizziness. In Ondansetron continuous infusion group there is an improvement of headache event from the second day of the third day, that is the third day only 1 patient having dizziness. In the Ondansetron bolus intravenous group, the relative intensity of a headache is comparable between patients who experienced improvement or remained dizzy on the third day. The results of measurements using computer analysis and showed no difference in side effects of dizziness on the second and third days.

The result of analytic analysis with EBM principle to know side effects of dizziness showed the risk of dizziness in continuous administration of a continuous infusion of $20 \%$ compared with ondansetron intravenous bolus. The results of the number need to harm $(\mathrm{NNH})$ analysis indicate the need administration of Ondansetron continuous intravenous to 5 samples to cause side effects of dizziness. The $\mathrm{NNH}$ value farther of 1 means the better, so $\mathrm{NNH}$ can be used as a drug side-effect parameter.

Measurement of differences in side effects of constipation is descriptive there are patterns in both groups of almost all patients constipation, there is only 1 patient in each group having defecation. The result of measurement using computer analysis aid shows no difference in both groups. This result is consistent with several studies, which suggest the side effects of Ondansetron and Morphine one of which is constipation $[15-18,21]$.

The result of analytical analysis with EBM principles to constipation risk on the Ondansetron continuous infusion. Increased risk of constipation in the continuous infusion group by $9.6 \%$, with actual difference between Ondansetron continuous infusion with an $8 \%$ bolus intravenous in causing side effects of constipation. The results of $\mathrm{NNH}$ analysis indicate the need an Ondansetron continuous infusion to 13 samples to cause side effects of constipation.

The emergence of side effects of dizziness and constipation in this study was made possible by the use of two kinds of drugs, 
namely Ondansetron and Morphine, so as to ensure more drugs that play a role in the emergence of side effects used measurements with Naranjo scale. The measurement results for each drug that had side effects of dizziness and constipation (ie Ondansetron and Morfin) got a score of 3 which means Ondansetron and Morfin are less likely to cause dizziness and constipation. In this study, ondansetron administration along with epidural morphine for 2 days. So it cannot be seen which drugs are more instrumental in causing side effects of dizziness and constipation.

Based on data on the side effects of itching, fined $4(23.5 \%)$ of the samples that experienced itching from a total of 17 samples. Naranjo scale measurement results for Morphine which has an itchy side effect gets a score of 9 which means most likely the side effects are caused by Morphine. The results of this study in accordance with some studies that mention side effects Morphine, one of which is the occurrence of itching. Moreover, the use of epidural Morphine alone can increase the risk of side effects such as nausea, vomiting, and itching. However, for the efficacy of therapy in overcoming postoperative pain is better than the use of parenteral $[9,19,21-23]$. The results of Kumar (2013) and Cottrell (2015) suggest that the use of opioids primarily through intrathecal and epidural pathways can cause itching [2425]. The results of Koju et al (2015) also demonstrated the use of Ondansetron $4 \mathrm{mg}$ bolus intravenous prophylaxis before the intrathecal Morphine administration was significant in reducing itching and nausea and vomiting compared with placebo [33]. The use of postoperative Ondansetron can provide two advantages, namely: to overcome the complaints of postoperative nausea and vomiting and reduce the side effects of the use of epidural Morphine in the form of itching. Some studies that have been done only comparing the efficacy of Ondansetron bolus intravenous with placebo. There has been no study comparing how the efficacy of Ondansetron continuous infusion with a bolus intravenous in reducing itching incidence. The results of this study may also indicate if the continued use of Ondansetron continuous infusion or bolus intravenous did not show a difference in reducing the incidence of itching after epidural morphine use.

The result of analytic analysis with EBM principle to know the side effect of Morphine in the form of itching showed if the itching risk on Ondansetron continuous infusion was lower $45,3 \%$ compared to Ondansetron bolus intravenous. The result of number need to harm (NNH) analysis indicates the need for administration of Ondansetron continuous intravenous to 7 samples to cause side effects of itching due to the use of Morphine

\section{CONCLUSION}


Based on the results of this study concluded that there is a difference in efficacy between the two groups, namely Ondansetron continuous infusion is more effective than bolus intravenous. Side effects that occur in Ondansetron group continuous infusion and bolus intravenous are dizziness and constipation. There were differences in side effects between the two groups, ie the risk of dizziness in the continuous infusion group was lower, but the side effects of constipation were higher.

\section{REFERENCES}

[1] Gan TJ, Diemunsch P, Habib As, Kovac A, Kranke P, Meyer Ta, Et Al. Consensus Guidelines For The Management Of Postoperative Nausea And Vomiting. Anesth Analg. 2014;118(1).

[2] Song SY, Et Al. Comparison between Bolus Injection and Continuous Infusion of Ondansetron on Nausea and Vomiting in Intravenous, Patient-controlled Analgesia after Laparoscopic-assisted Vaginal Hysterectomy using Propofol and Remifentanil Anesthesia. Korean J Anesthesiol. 2008 Apr;54(4):422-426.

[3] Jolly M, Sebire N, Harris J, Robinson S, Regan L. The Risk Associated with Pregnancy in Women Aged 35 Years or older. Human reproduction. 2000; Vol. 15 No.11.

[4] Pierre S, Whelan R. Nausea And Vomiting Postoperative. Contin Educ Anaesth Crit Care Pain [Internet]. 11 Agustus 2012.

[5] Islami S, Jain P. Post-Operative Nausea, And Vomiting (Ponv). A Review Article. Indian J Anaesth. 2004;48(4):253-8.

[6] Halpern S, Walsh V. Epidural Ropivacaine vs Bupivacaine for Labor: a
Meta-Analysis. Obstetric Anaesthesia. 2003

[7] Lavery I. Intravenous Therapy And Infusion Devices; Pre-Course Workbook. Nhs. 2012.

[8] Piche AC, Fan M, Sabovitch S, Masino C, Easty A. Multiple Intravenous Infusions, Phase 1b : Practice And Training Scan. Health Qual Ont. 2012;12(16):1-132.

[9] Swierzewski SJ. Before and Postoperative. 2001.

[10] Moon YE, Joo J, Kim JE, Lee Y. Antiemetic effect of ondansetron and palonosetron in thyroidectomy: a prospective, randomized, double-blind study. British Journal of Anaesthesia. 25 January 2012.

[11] Bonnet MP, Mignon A, Mazoit JX, Ozier Y, Marret E.. Analgesic efficacy and adverse effects of epidural morphine compared to parenteral opioids after elective caesarean section: a systematic review. Eur $J$ Pain. 2010.

[12] Mercanoglu E, Alanoglu Z, Ekmekci P, Demiralp S, Alkis N. Comparison of intravenous morphine, epidural morphine with/without bupivacaine or ropivacaine in postthoracotomy pain management with patient controlled analgesia technique. Rev. Bras. Anestesiol. 2013; vol.63 no.2.

[13] Craig M, Nogami WM, Van Maren G, Alves DM. Postcesarean Epidural Morphine: A Dose Response Study. Anesthesia \& Analgesia. April 2000, vol. 90 no. 4 887-89.

[14] Smith HS, Smith JM, Seidner P. Opioidinduced nausea and vomiting. Review article. Annals of Palliative Medicine. Juli 2012; Vol 1, No 2.

[15] Becker D. Nausea, Vomiting, And Hiccups: A Review Of Mechanism And Treatment. Aesthesia Progressn. 2010;57:150-7.

[16] Medicines And Healthcare Product Regulatory Agency. Ondansetron. 
Safeguarding Public Health. 2006.

[17] Lullmann H, Mohr K, Ziegler A, Bieger D. Color Atlas Of Pharmacology. 2 Ed. Revised And Expanded; 2000.

[18] Abouleish E., Rashid S, Haque S, Giezentanner A, Joynton P, Chuang A. Ondansetron Versus Placebo For The Control Of Nausea And Vomiting During Caesarean Section Under Spinal Anaesthesia. 1999;54(5):479-82.

[19] Carvalho FAE, Tenorio SB. Comparative study between doses of intrathecal morphine for analgesia after caesarean. Elsiever. Received 16 December 2012; accepted 10 January 2012.

[20] The Royal College of Anaesthetists (RCoA) and The Association of Anaesthetists of Great Britain and Ireland (AAGBI). Headache after an epidural or spinal anaesthetic. Fourth edition July 2012

[21] Swegle JM, Logemann C. Management of Common Opioid-Induced Adverse Effects. Am Fam Physician. 2006 Oct 15;74(8):1347-1354

[22] Halpern S, Walsh V. Epidural Ropivacaine vs Bupivacaine for Labor : a Meta Analysis. Obstetric Anasthesia. 2003.
[23] Flisberg P, Rudin A, Linnér R, Lundberg CJ. Pain Relief and Safety After Major Operative a Prospective Study of Epidural and Intravenous Analgesia in 2696 Patient. Acta Anasthesiol Scand 2003.

[24] Kumar K, Singh SI. Neuraxial opioid-induced pruritus: An update Journal of Anaesthesiology Clinical Pharmacology. July-September 2013; Vol 29 Issue 3.

[25] Cottrell BH. A Review Of Opiod Induced Itching After Caesarean Birth. Nursing For Woman Health.2015; Volume 19 Issue 2.

[26] Koju RM, Gurung BS, Dongol Y. Prophylactic administration of ondansetron in prevention of intrathecal morphine-induced pruritus and postoperative nausea and vomiting in patients undergoing caesarean section. BMC Anesthesiology 2015, 15:18. 